\title{
Analysis on the Demand Structure of Postgraduates in Classroom Teaching
}

\author{
Tong Zhou \\ Shandong Technology and Business University, Yantai, 264005, China \\ zhout6977@foxmail.com
}

Keywords: postgraduates, classroom teaching, learning needs

Abstract: As an important part of higher education in our country, the teaching status of postgraduates has been paid much attention by the society. The paper investigates the course setting, content, method and effect in the course of postgraduate teaching. Result display a single teaching model for postgraduates, lack of character, dull atmosphere in classroom teaching, lack of initiative in graduate participation, and lack of practical and leading teaching content. It is difficult to arouse students interesting, management of teaching is relatively loose, and enthusiasm of postgraduates is insufficient.

\section{Introduction}

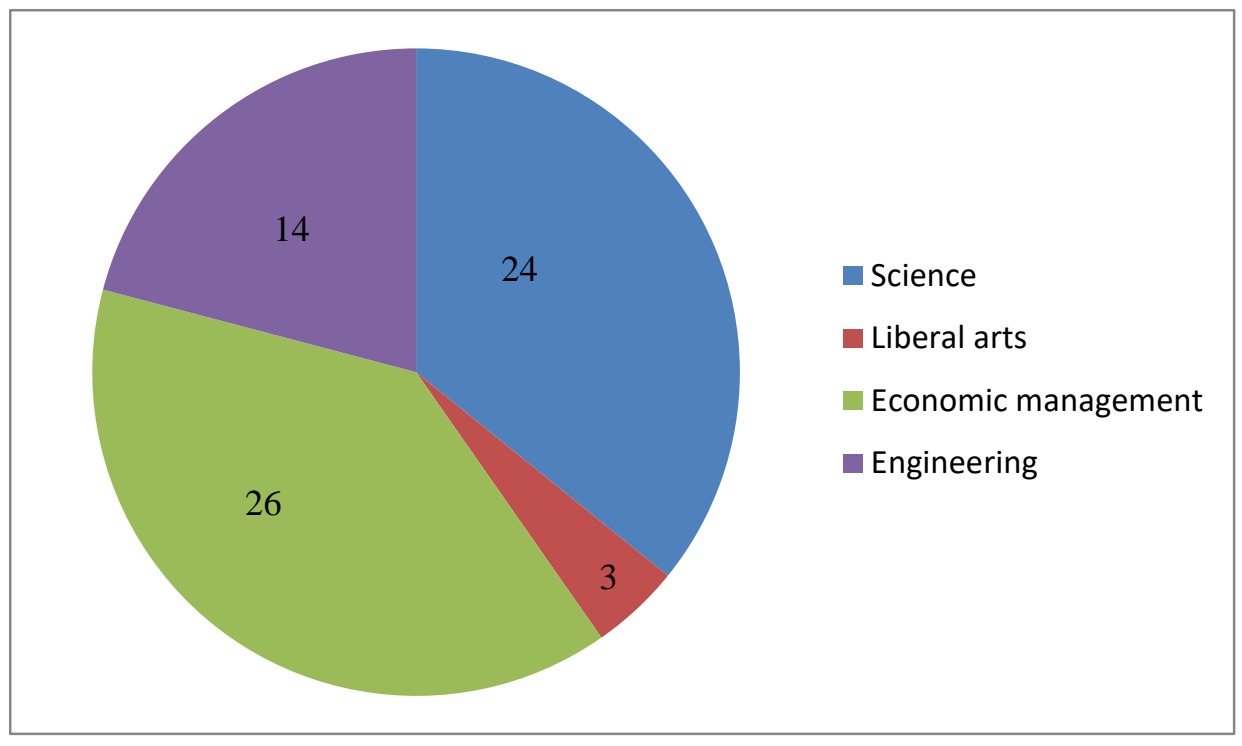

Figure 1 Research on the distribution of postgraduates participating

China has expand its enrollment of postgraduates since 2009, the rapid growth of the number of postgraduates meets the high-level talents of the society, but also makes the limited educational resources of colleges and universities under pressure. On the basis of ensuring the quality of graduate education, how to carry out effective teaching reform has become an important subject for 
graduate education. The purpose of the research is to analyze the present situation of postgraduates' classroom teaching to find out the problems in teaching, and provide reference for further improving the graduate's classroom teaching model. Questionnaire survey for postgraduates from our university by network form, the content is divided into four parts: course setting, teaching content, teaching method and teaching effect, 77 valid questionnaires received. (As shown in figure1)

\section{Postgraduate course setting}

Postgraduates are not only learners of higher education, but also play the role of academic research and innovation. Autonomy and innovation are the necessary ability of modern academic research and the core content of postgraduate education. So, Scientific and effective curriculum setting is an important guarantee for the cultivation of graduates students' academic ability. Survey data show ( As shown in table 1) , 42.36\% of the students think that the curriculum goals and requirements in graduate teaching are not very clear, there is no good orientation according to the characteristics of academic practice, practicality and complexity of the major. $12.22 \%$ of the students questioned the reasonable arrangement of the required course and elective course, and thought that the time and content for the same course should be different without the specialized graduate. $40.23 \%$ of the students think that the number of courses available is too short and the curriculum arrangement is not reasonable. $41.36 \%$ of the students think that some courses are not targeted. No difference among specialized courses. In terms of the rationality of the scheduling of courses, $76.68 \%$ of the students are still acceptable, which has little to do with the whole period of graduate study.

Table 1 Survey data of postgraduate course setting

\begin{tabular}{llccc}
\hline Item & Good & General & Bad & $\begin{array}{c}\text { Not } \\
\text { Clear }\end{array}$ \\
\hline Clarity & $22.42 \%$ & $33.42 \%$ & $18.94 \%$ & $15.22 \%$ \\
Effectiveness & $37.11 \%$ & $40.23 \%$ & $12.22 \%$ & $10.44 \%$ \\
Pertinence & $36.24 \%$ & $41.36 \%$ & $13.12 \%$ & $9.28 \%$ \\
Rationality & $20.44 \%$ & $56.24 \%$ & $10.16 \%$ & $13.16 \%$ \\
\hline
\end{tabular}

The answer to open question, someone suggest that according to the needs and reasonable teaching resources of configurations, to reduce unnecessary theoretical courses (such as politics courses), and increase the number of applied courses and related teachers. Moreover, about $10 \%$ of postgraduates make choice between the different options; this may also indicate that some postgraduates are not clear about their own needs. Meanwhile, there is not enough attention to the training plan of the school and the curriculum.

\section{Teaching content}

The teaching content is the foundation of postgraduate's taming professional knowledge, and it is also a shortcut for postgraduates to have scientific research thinking and understand the frontiers of professional science and technology, classroom teaching is an effective way to improve the level of graduate student's scientific research. From the survey date of table 2, postgraduates are not well on all aspects of teaching content, overall satisfaction is below 70\%. Among these, only $50.46 \%$ of the students are satisfied with the teacher's preparation for teaching. On the other hand, the satisfaction degree of teacher courseware design and language expression is $60.24 \%$ and $62.36 \%$ respectively, it shows that some teachers are not strict enough in their attitude to the teaching of postgraduates; the 
degree of satisfaction involved in the research, innovation and the teaching of the leading results is $54.4 \%$, lag behind their learning needs. Because the teachers have the title of vice-senior or above, they have a higher level of logical expression, therefor, the content of teaching in the logical aspect of satisfaction reached $66.24 \%$. $68.24 \%$ of the students expressed satisfaction with the suitability of the teaching schedule.

Table 2 Survey data of classroom teaching contents

\begin{tabular}{lllll}
\hline Item & Good & General & Bad & $\begin{array}{c}\text { Not } \\
\text { Clear }\end{array}$ \\
\hline Preparation & $50.46 \%$ & $35.24 \%$ & $5.64 \%$ & $8.66 \%$ \\
Reasonable & $60.24 \%$ & $28.86 \%$ & $4.23 \%$ & $6.67 \%$ \\
Accurately & $62.36 \%$ & $27.45 \%$ & $4.63 \%$ & $5.56 \%$ \\
Logicality & $66.24 \%$ & $20.86 \%$ & $7.66 \%$ & $5.44 \%$ \\
Foreland & $54.40 \%$ & $22.46 \%$ & $10.24 \%$ & $12.90 \%$ \\
Suitability & $68.24 \%$ & $27.24 \%$ & $4.52 \%$ & 0 \\
\hline
\end{tabular}

Combined with the answers to the questions, the postgraduates have just passing the evaluation, which shows that the quality of classroom teaching needs to be further improved. Moreover, it can be seen that the students who have just separated from the examination-oriented teaching mode need to experience the new one. This puts forward a better request to the graduate student's teaching and reflects their yearning for innovation.

\section{Teaching methods and effects}

The method is the soul of teaching, scientific methods can make teaching double effective. Data of table 3 tell us only $7.24 \%$ of the postgraduates can teach in class according to their aptitude; it shows that our teaching system is very difficult to do that. To recommend professional related bibliographies and effectively guide postgraduates accounted for $52.36 \%$, those who can relate theory to practice account for $46.42 \%$, flexible use of case teaching accounted for $55.64 \%$, and can carry out classroom discussion, the realization of interaction accounted for $36.44 \%$. According to the above, the classroom teaching of postgraduates can achieve the use of reasonable and effective methods basically, and the effect is obvious.

Table 3 Survey data of teaching method

\begin{tabular}{|c|c|c|c|c|c|}
\hline Item & & Good & General & Bad & $\begin{array}{c}\text { Not } \\
\text { Clear }\end{array}$ \\
\hline $\begin{array}{l}\text { Teach } \\
\text { accordance } \\
\text { student's } \\
\text { aptitude }\end{array}$ & $\begin{array}{l}\text { in } \\
\text { of }\end{array}$ & $7.24 \%$ & $18.62 \%$ & $66.24 \%$ & $7.90 \%$ \\
\hline $\begin{array}{l}\text { Active } \\
\text { guidance }\end{array}$ & & $52.36 \%$ & $34.20 \%$ & $11.24 \%$ & $2.2 \%$ \\
\hline $\begin{array}{l}\text { Combine } \\
\text { theory } \\
\text { practice }\end{array}$ & $\&$ & $46.42 \%$ & $30.24 \%$ & $18.34 \%$ & $5.00 \%$ \\
\hline Interaction & & $36.44 \%$ & $40.32 \%$ & $21.32 \%$ & $1.92 \%$ \\
\hline Case study & & $55.64 \%$ & $24.76 \%$ & $16.18 \%$ & $3.42 \%$ \\
\hline
\end{tabular}


Research on the teaching effect ( Table 4 shows ), 46.68\% of postgraduates think that they can master the main teaching content basically through classroom teaching and keep abreast of the latest developments; $67.44 \%$ feel that their ability to analyze and solve problems has improved; but only $38.34 \%$ have increased their interest in learning, and there are only $41.26 \%$ postgraduates who can innovate and think。 This shows, classroom teaching can meet students' knowledge and cultural needs. However, the cultivation of innovation and creative ability has yet to be improved.

Table 4 Survey data of teaching effect

\begin{tabular}{|c|c|c|c|c|}
\hline Item & Good & General & Bad & $\begin{array}{c}\text { Not } \\
\text { Clear }\end{array}$ \\
\hline Content & $46.68 \%$ & $40.24 \%$ & $10.22 \%$ & $2.86 \%$ \\
\hline $\begin{array}{l}\text { Analysis } \\
\text { Resolution }\end{array}$ & $67.44 \%$ & $21.32 \%$ & $11.24 \%$ & 0 \\
\hline Interest cultivation & $38.34 \%$ & $32.72 \%$ & $20.12 \%$ & $8.82 \%$ \\
\hline $\begin{array}{l}\text { Innovation } \\
\text { Thinking }\end{array}$ & $41.26 \%$ & $33.52 \%$ & $16.54 \%$ & $8.68 \%$ \\
\hline
\end{tabular}

\section{Reflection and discussion}

Such a fact can be found after investigation and analysis: Graduate class teaching is not a cramming style, the interaction between teachers and students is universal, but the practice is weak, the effect is not well, and the student satisfaction is low, etc.

\subsection{Optimize course setting}

The methods and contents are integrated in classroom teaching, they are interdependent and mutually reinforcing. Therefore, the curriculum design must be reasonable, and according to different characteristics, select the appropriate teaching methods, to strengthening the research of curriculum setting, optimizing educational resources, and constructing reasonable curriculum system; to Strengthening the research and discussion of curriculum design, aim at cultivating innovative and creative postgraduates, exploring the curriculum suitable for the specialty characteristic.

\subsection{Enrich teaching methods}

Although the model has shown the characteristic of diversity and is still being upgraded, but we shouldn't satisfied with status quo and stop moving forward. Teaching method will show vitality only by increasing new blood. In the rapidly changing society, we should accelerated the renewal of teaching methods, so we must actively introduce more new teaching methods and enrich it. It is not only benefit students, but also enhance the core competitiveness of school, education even society.

\subsection{Explore new teaching model}

In our country, classroom education presents the teaching mode which takes the teacher as the main body. Although the model has its unique characteristics, in a particular class will show extraordinary teaching results, but ignored the students. However, we can find that the teaching mode of one teacher is not conducive to the exploration and development of graduate autonomy and innovation after understanding the particularity of graduate teaching. Therefore, we should start from the actual situation and work out the teaching model which is suitable for postgraduates. 
Among the process of creating new teaching mode, we must take postgraduates as the foundation; we should pay attention to the inheritance and the creation of knowledge.

\subsection{Establish dynamic feedback mechanism}

Teaching is not an isolated activity. It is necessary to get feedback if we want to understand if the method is suitable for the course and whether the students accept it. We must set up feedback mechanism or regular research on the latest trends, so as to be able to adjust the teaching method effectively. Such process not only understanding method and the situation of classroom teaching, but also contributes to the further discussion of the activities and form interaction between teachers and students.

\section{References}

[1] Ernest A. Lumsden, Joseph H. Grosslight, Edward H. Loveland, et al. Preparation of Graduate Students as Classroom Teachers and Supervisors in Applied and Research Settings. [J]. Teaching of Psychology, 15(1):5-9, (1988).

[2] Thomas R, Quinlan E. Teaching and Learning Focus Group Facilitation: An Encounter with Experiential Learning in a Graduate Sociology Classroom [J]. Transformative Dialogues Teaching \& Learning Journal, (2014).

[3] O'Loughlin, Dean V, Braun, et al. Can we encourage our graduate students to develop a more scholarly approach to classroom teaching? [J]. The FASEB Journal, 22(12): (2008).

[4] Deng Y L, Xiao C G, Tang Q P, et al. Application of displacement research teaching model in postgraduate classroom teaching [J]. China Higher Medical Education, (2006). 